\title{
Development of intelligent road maintenance system mobile apps for a highway
}

\author{
Nurul Husna Mohd Jamail ${ }^{1}$, Abdul Halim A. G $^{2}$, Nor Shahida Mohd Jamail ${ }^{3}$ \\ ${ }^{1,2}$ Department of Civil Engineering \& Built Environment, Universiti Tun Hussein Onn Malaysia, Malaysia \\ ${ }^{3}$ College of Computer and Information Sciences, Prince Sultan University, Saudi Arabia
}

\begin{abstract}
Article Info
Article history:

Received Mar 16, 2020

Revised May 25, 2020

Accepted Jun 7, 2020

\section{Keywords:}

Highway

Intelligent

Mobile application

Road maintenance

Toll expressway

ABSTRACT

Roads are one of the main assets of a country where the network infrastructure offers economic and social benefits. It is understood that road maintenance would improve economic development and social benefits, and the poorly maintained road network would destruct mobility, raise accident rates, intensify isolation, poverty and vehicle operating costs. Unidentified road environment covers many aspects and based on that matter, it is important to improve the quality of inspection reports, whereby the efficiencies by mobile application shall be utilized. Developed system mobile apps have been found to be effective, versatile to use, as they can be used anywhere and at any time. The goal was therefore to recognize the types of defects, issues and deficiencies in current road maintenance practices and to develop a computerized highway maintenance program. The scope of the research will be limited to a case study at PLUS highway, connecting the north and south highway of peninsular Malaysia. The findings showed that road maintenance work is not adequately and effectively designed because it requires more time and includes a lot of paperwork. Due to this matter, the proposed mobile application would provide an invaluable added benefit to intelligent system of PLUS highway.
\end{abstract}

This is an open access article under the CC BY-SA license.

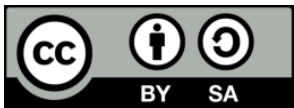

\section{Corresponding Author:}

Nurul Husna Mohd Jamail,

Department of Civil Engineering \& Built Environment,

Universiti Tun Hussein Onn Malaysia,

86400 Parit Raja Batu Pahat Johor, Malaysia.

Email: nurulhusnamj@yahoo.com

\section{INTRODUCTION}

Roads are transport infrastructures which play an important role in promoting the economic development of the region [1]. As per [2], roads are expanding across the globe at a phenomenal rate, both in all lengths and in all area where the length of legally permitted roads, as expressed in [3], has increased by 12 million $\mathrm{km}$ worldwide since the year 2000. Citizens will benefit a lot from improving the highways. To order to preserve these benefits, the construction of the highway must be followed by a well-planned maintenance control program. Maintenance may have been first defined by the British Standard in 1964 or recognized as BS 3811:1964. As "work undertaken in order to keep or restore every facility to an acceptable standard" [4]. Without frequent maintenance, roads will easily fall into disrepair, preventing the longer-term effect of road construction on development as well as the social and economic growth of the country. Constructing new roads cost money, but without maintaining the existing roads properly, they deteriorate very quickly. This deterioration will very fast affect road transport in general [5].

In Malaysia, damaged pavement is known to be one of the main contributors to the fatal crash of a motor vehicle [6]. As a result, public (functional or structural) road failures present a danger to vehicle drivers [7], who are faced with an increasing risk of accidents like road damage, such as surface cracking or 
potholes, becoming more serious [8]. Therefore, good road conditions must be maintained to encourage road safety; road damage not only leads to accidents but is also costly in terms of cyclic and responsive maintenance [9]. A study from [10], mentioned some other factors that contribute to the defect of the roads. These factors are heavy traffic, natural catastrophes (heavy rain and flood), improper maintenance, imperfection in construction, road design problems, low quality in materials used in road construction and inefficiency of controlling and monitoring. According to [11], delayed or postponing road maintenance results in high direct and indirect costs. If road defects are repaired promptly, the cost is usually modest. If defects are neglected, an entire road section may fail completely, requiring full reconstruction at very high cost, compared to the maintenance costs.

Highways infrastructure and its provision have a significant impact on economic growth and its development is reflected in the economic well-being of the country as well as bringing important social benefits. Therefore, an efficient maintenance management system is needed in order to maintain, repair and restore the invaluable highway assets. Road maintenance comprises of activities to keep pavement, slopes, drainage facilities and all other structures and property as near as possible to their as constructed or renewed condition. According to [12], the maintenance of roads famously known could enhance the economic growth and social benefits though road system that poorly maintained destructs mobility, upsurges the accidents rate, and worsens other main aspects. Forster and Mensah [13] believe that road maintenance is an essential short-term transport policy that policymakers need to pay attention to because it helps to enhance road safety and improves the social welfare of the citizenry. Without proper maintenance, the highway will become easy to failure in short term where will also lead to the increasing of traffic accident. For proper management and operational convenience, road maintenance is categorized as routine, periodic, and urgent [14]. According to [15], even though road maintenance is an extensive open administration that influences all residents, yet generally, it is made do with almost no utilization of information technology aside from radios, computer records, and networking which makes road maintenance tasks less economical and road conditions less sheltered than they could be.

The various types of defects found and listed have been classified by the Malaysian Highway Authority (MHA) according to the functional category of the expressway, namely road surfaces, drainage systems, structures, earthworks and road safety furniture. The PLUS Expressways or PLUS Malaysia Berhad (PMB) is the acronym of Projek Lebuhraya Usaha Sama Berhad (PLUS) formerly known as Projek Lebuhraya Utara Selatan Berhad. It is the largest highway concessionaries company in Malaysia connection North and South of peninsular Malaysia which launched in 1986. PLUS Expressways covers the New Klang Valley Expressway, Federal Highway Route 2, Butterworth-Kulim Expressway, Malaysia- Singapore Second Crossing, Seremban-Port Dickson Highway and the North-South Expressway Central Line. The Malaysia Highway Authority has launched the Tollroads Evaluation and Monitoring System (TEAM) version 2. However, this system is not a mobile apps but a software system integrating the database to users through online process. This tool focused more highway road pavement performance as stated in their published conference paper [16], an earlier version of the TEAM system.

Nowadays, everything can be informed via the internet, which can be done in many ways, such as through web sites, social media, e-mail and others. Mobile applications, popularly referred to as mobile apps, re that are typically programmed to run on smartphones [17] and tablets computer system [18]. Mobile apps are tools to get information via internet. These mobile apps are normally run on the Google Android and Macintosh iPhone system. While [19] believe, this technique offers the possibility to blend the output and road framework data from different vehicles to empower a progressively strong and exact forecast of the ground truth. Academic publications in Malaysia stressed more on the usage of smartphones in Malaysia. Reference [20] is a survey study of the current dynamics of the Malaysian market for smartphones and the usage behaviours of consumers. This journal did extend on media usage of smartphones which is indirectly refer to the usage of mobile apps. With the exponential growth of information in the internet, it is very essential to consolidate the related information and to present the contents in a concise manner [21].

Most of the available existing mobile apps concentrate only for the traffic information. The PLUS mobile app is the official PLUS mobile app created by PLUS Malaysia Berhad to provide Malaysian highway users with the most reliable traffic routing, road warnings and facilities available along the PLUS highway. The Malaysian Highway Authority has a similar program called LLM traffic data. Intelligent road maintenance system (IRMs) yet still not be implemented. This research target that the highway maintenance management system will be more systematic and comprehensive and it will helps in storing online of data outside computer context and becomes part of our daily life [22] when using the IRMs mobile apps. According to [18], mobile applications, also called mobile apps, are software applications, usually designed to run on smart phones and tablet computers. When a connection becomes available, the data is synchronized to update the highway databases that allow users to take advantage of the operational efficiencies even in remote locations. IRMs mobile apps will provide an optimum scheduling 
of highway maintenance activities and improve the cost effectiveness of a management system. Hence, the mobile app proposed in this study will be an invaluable added value to intelligent system of PLUS highway. IRMs also will eliminate the manual paper and the usage of this application will be providing valuable, quality road survey reports daily, which will include photographs of the roads to and extent of repairs needed.

\section{RESEARCH METHOD}

There are two methods used by the researcher to achieve the objective of this study. The first method that applied was through the literature review by gathering knowledge of this study to get a clear framework. For the second method, surveys were conducted through the distribution of structured questionnaires among the targeted respondents such as PLUS Berhad, MHA, UEM EDGENTA PROPEL, engineers and road user to obtain feedback from the road maintenance industry. According to [23], this test is vital in order of ensuring the questions' reliability especially is the choice of words have been done properly, while the meaning of projected sentences is relevance with each statement probed.

\subsection{Research design}

The studies were further done to identify and understand the equipment, algorithm environment and tools necessary for testing the software with the related maintenance application. As the purpose of this study is measure the highway maintenance management system and to attempt in digitalizing the system through the Mobile Apps platform, a research design is essential which works as the fundamental commands in conveying the research project [24]. According to [24], quantitative approach aids to offer review information on several characteristics that become more useful for testing. The research design can be summarized as depicted in Figure 1 to get a clear framework and will be explained further.

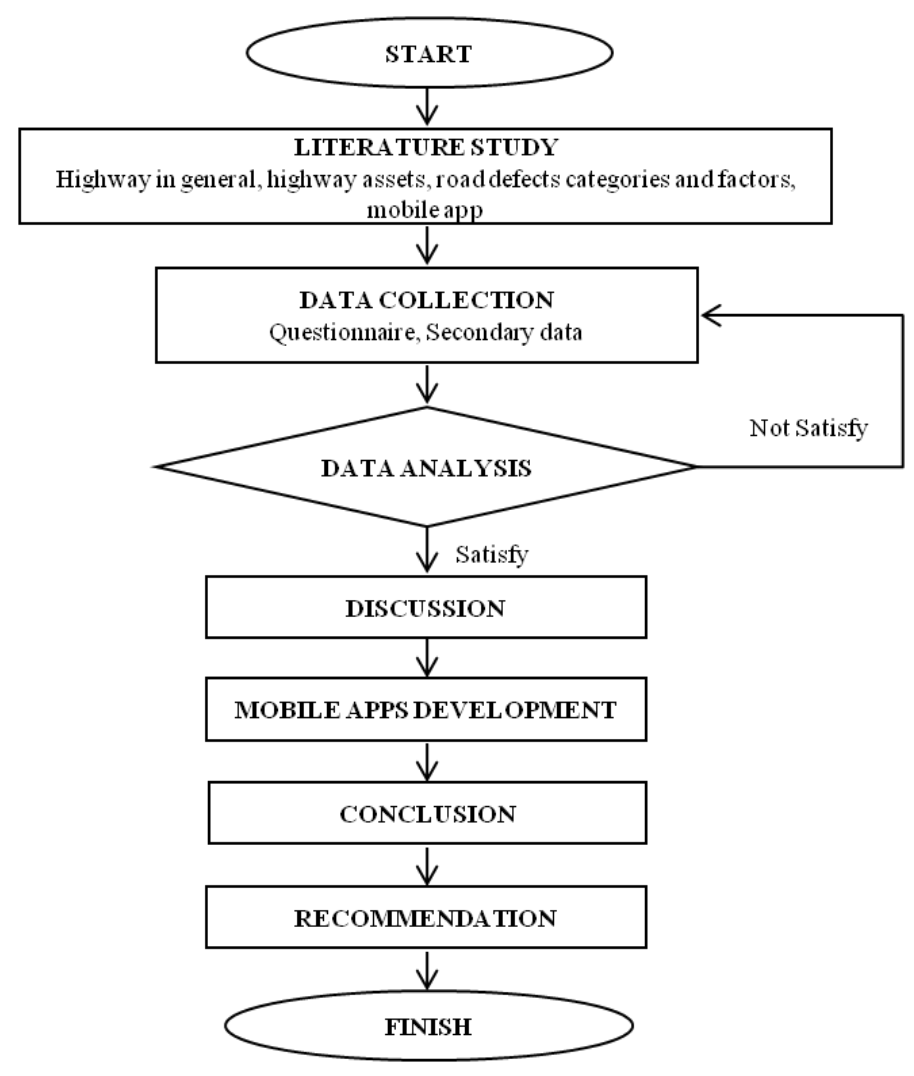

Figure 1. Research design flowchart

The literature review has been done on the perspective on the nature of the highway maintenance management. These reviews include highways assets, highway road defects and the insights of mobile application and its implementation in highway maintenances management system. Based on the literature 
review, the development of a research instrument has proceeded as the instrument for data collection in this study before the analysis process could be implemented. Based on primarily studies that include mobile apps development, review on maintenance management research and industry of highways, particularly in Malaysia and some other parts of the world, the mobile apps must cater with all necessary maintenance of the highway.

All data and information related to the study will be collected and divided into two categories such as questionnaire and secondary data. This questionnaire method was administered to obtain data practically where the actual situations occurred. Questionnaires are distributed to PLUS Berhad, The MHA, UEM EDGENTA PROPEL and road user. This questionnaire has been distributed among the 400 targeted respondents for data gathering. This data will analyze in the quantitative method as an input for the mobile application development. The data obtained from reading materials and reference literature such as books, journals, newspaper articles, conference papers, reports etc. The use of this data is to confirm all information and other details can be used in the final analysis of this research. The personally administered questionnaire is the most appropriate instruments as it consumes a brief period for data collection with minimal cost. By implementing this approach, it will allow the researcher to assist the respondents if they have any doubts or questions about the items in the questionnaire [25]. Secondary data was obtained through literature, references such as books, journals, conference papers, newspapers, reports, internet surfing etc.

Data analysis is the most critical aspect of the study. The data analysis summarizes the data obtained. This includes the analysis of data obtained using empirical and logical reasoning to determine patterns, relationships or trends. All the data collected and received will be compiled and analyzed using statistical package for social science (SPSS) 21.0 according to the average index of the objective and scope of research. Table will be used to describe and interpret data. The results of the analysis, processing and findings obtained types and factors of defects and digitalize the system through the mobile apps platform. The data collected on the levels types and factors was tabulated based on the number of responses for each category. The results will be described in descriptive statistics by means of frequency counts and percentages, illustrated in tables to give a clear picture of the outcome questionnaire. As a result, it can be inferred that all data can be used as a database when creating mobile apps. The application developed according to the normal software development cycle and system. A user interface design (UI) or user interface engineering will be design for machines and software application. User stories or UI explain how the end user is supposed to use the app in general and each of its features. In this proposal the data analysed from questionnaire will be structured to feature in the apps. These will the guidelines in the app development process. The development of this app will be based on the data collection from questionnaire

Data collected from questionnaire and development of mobile apps can be conclude as a part explaining method of methodology for research that carried out. It begins from the study design, instrument and analysis technique, this part explains how this objective study can achieve. Data that achieved from questionnaire distribution will be analysed by SPSS. With the believe of the applied methodology, this methodology can help the researcher to produce the data findings to answer the research questions and then to achieve the objectives. With proposed these mobile apps it can focus on maintenance issues specific to PLUS highways. These apps will allow users to mark the problem location on a map and upload a photo of the issue.

\subsection{Research instrument}

A self-completed questionnaire has been planned in gathering the required information before the questionnaire distributed. The questionnaire form was prepared in a booklet by using English language. Each question in this questionnaire was developed and adapted based on the variables specified in the framework from the earlier study. Some of the questions have been modified in simple and direct words to help the respective respondents easy to understand and answering. The designed questionnaire comprises 53 questions, which divided into six sections part A demographic profile, part B type of defect, Part C factor of defect, Part D suggestion for implementation of management system, Part E enhancement of maintenance system and Part F method of maintenance road effect. These questions are formed from close-ended question. The arrangements of questionnaire can be summarized in the Table 1.

Table 1. Arrangement of development questionnaire

\begin{tabular}{lll}
\hline Section & Description & Number of question \\
\hline Part A & Demographic profile & 6 \\
Part B & Type of defect & 12 \\
Part C & Factors of defect & 11 \\
Part D & Suggestion for implementation of management system & 7 \\
Part E & Enhancement of maintenance system & 6 \\
Part F & Method of maintenance road effect & 11 \\
Total number of questions & 53 \\
\hline
\end{tabular}


A Likert scale was applied for rating scale. Multiple choice questions been used in Part B to Part E by using 5-point scale ranging from number 1 represents 'Strongly Disagree', number 2 represents 'Disagree', number 3 represents 'Moderate', number 4 represents 'Agree' and number 5 represents 'Strongly Agree'.

\section{RESULTS AND DISCUSSION}

The data presented and visualized are obtained from SPSS. The data analysis discussed is regarding the improvement of the PLUS Highway Maintenance System. Data were gathered from 400 respondents using a questionnaire survey method. All the date gathered will interpret into mobile application system. Figure 2 shows the summary mobile apps that can be used for road maintenance team and road user because this apps sharing the same database. Content in maintenance apps of IRMs consist schedule road maintenance, reporting road maintenance, ongoing maintenance, result after maintenance and maintenance budget. User apps it consists reporting road problem with location mapping, calendar events, reviews, and social media link.

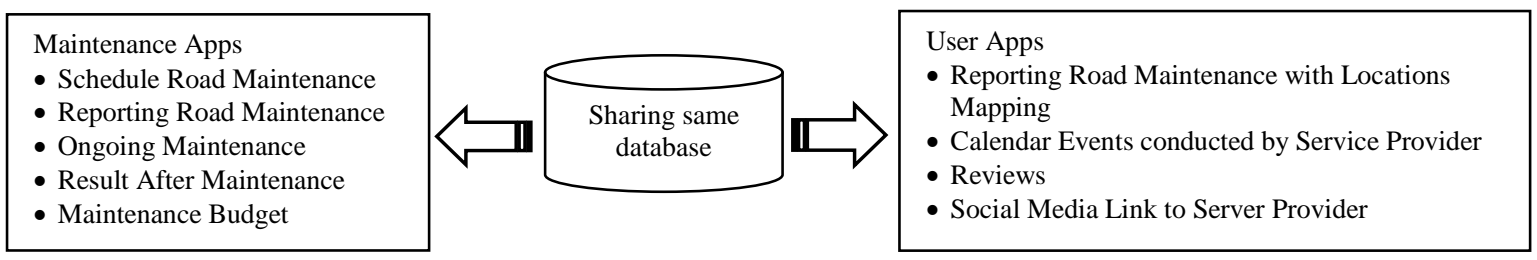

Figure 2. Maintenance apps and user apps

\subsection{Questionnaire analyses}

Table 2 shows the result on descriptive analysis for Part B in Table 1. The highest mean is crack due to pressure from vehicle which is 3.92. Most responses agree that crack at the highway always happen in Malaysia. All item in Table 2 will categorize in damage categories based on rating criteria. The highest mean will categories as high priority repairs means need immediate attention required due to traffic safety needs. Moderate means will categories as moderate priority repairs. Meanwhile the lowest mean will categorize as less priority repairs. Table 3 shows suggestion for improvement of maintenance system. From analysis has been done, researcher achieves the objective of this study which to develop mobile apps for road maintenance. The highest mean is creating an effective and comprehensive mobile application which is 4.33. It means that the responses agree mobile apps development will improve the road maintenance system. This is because mobile Apps such as LLM traffic and PLUS app just focusing on traffic information, emergency hotline, toll fare and etc.

Table 2. Descriptive analysis for types of defect

\begin{tabular}{lll}
\hline Items & \multicolumn{2}{l}{ Types of defect } \\
& Mean & Std. dev \\
\hline $\begin{array}{l}\text { Cracks due to pressure from vehicle } \\
\text { loads }\end{array}$ & 3.92 & 0.724 \\
Indentation due to poor road & & \\
construction work & 3.32 & 0.992 \\
$\begin{array}{l}\text { Potholes } \\
\text { Bumpy or uneven road surface }\end{array}$ & 3.50 & 0.907 \\
Blocked drainage system & 3.66 & 0.771 \\
Broken edge of the road due to the road & 3.24 & 0.772 \\
shoulder settlement & 3.40 & 0.756 \\
$\begin{array}{l}\text { Premix deprived as a result of } \\
\text { the pavement work done during rain }\end{array}$ & 3.37 & 0.774 \\
$\begin{array}{l}\text { Dividers damaged due to vehicles } \\
\text { collisions }\end{array}$ & 3.61 & 0.790 \\
Landslides or erosion & & \\
Ground settlement & 3.56 & 0.776 \\
Damage highway signage & 3.58 & 0.778 \\
Road lighting does not work & 3.27 & 0.897 \\
Overall Mean & 3.41 & 0.907 \\
\hline
\end{tabular}

Table 3. Maintenance method for road defect

\begin{tabular}{lll}
\hline Items & \multicolumn{2}{l}{ Types of defect } \\
& Mean & Std. dev \\
\hline $\begin{array}{l}\text { Perform road enhancements } \\
\text { quickly and continuously }\end{array}$ & 4.22 & 0.606 \\
$\begin{array}{l}\text { Improve service against } \\
\text { complaints received from } \\
\text { highway users }\end{array}$ & 4.23 & 0.597 \\
$\begin{array}{l}\text { Create an organized planned } \\
\text { work schedule }\end{array}$ & 4.28 & 0.550 \\
$\begin{array}{l}\text { Must be committed to perform } \\
\text { maintenance work if asset } \\
\text { damage complaint is received }\end{array}$ & 4.26 & 0.610 \\
$\begin{array}{l}\text { Tolled highway system needs be } \\
\text { maintained }\end{array}$ & 3.31 & 1.099 \\
$\begin{array}{l}\text { Create an effective and } \\
\text { comprehensive mobile } \\
\text { application }\end{array}$ & 4.33 & 0.780 \\
Overall Mean & 4.08 & 0.464 \\
\hline
\end{tabular}




\subsection{User apps}

Figure 3 shows the content in road user apps. Road user can make a report on road issues through mobile apps and maintenance team will get the immediate report via email. Any road defect shall be pointed via mapping of location detail once they make a report. Road user can get notification of any info on what is happening along the highway to be more alert. Maintenance team shall be able to communicate with user once they received any complaint from the road user.

\subsection{Intelligent road maintenance system (IRMs) mobile app}

In order to ensure the road maintenance works properly and efficiently planned without involve a lot of paperwork, the proposed of IRMs mobile apps will be value added to road maintenance system. Figure 4 shows the structure in mobile apps. The structure includes schedule road maintenance, reporting road maintenance, ongoing maintenance, result after maintenance and maintenance budget.

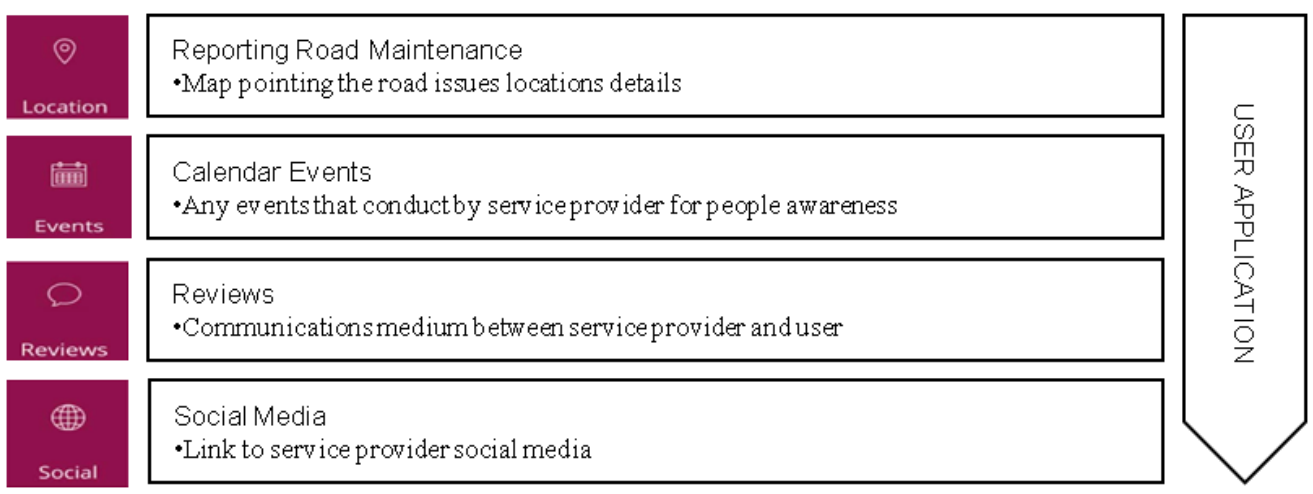

Figure 3. User apps

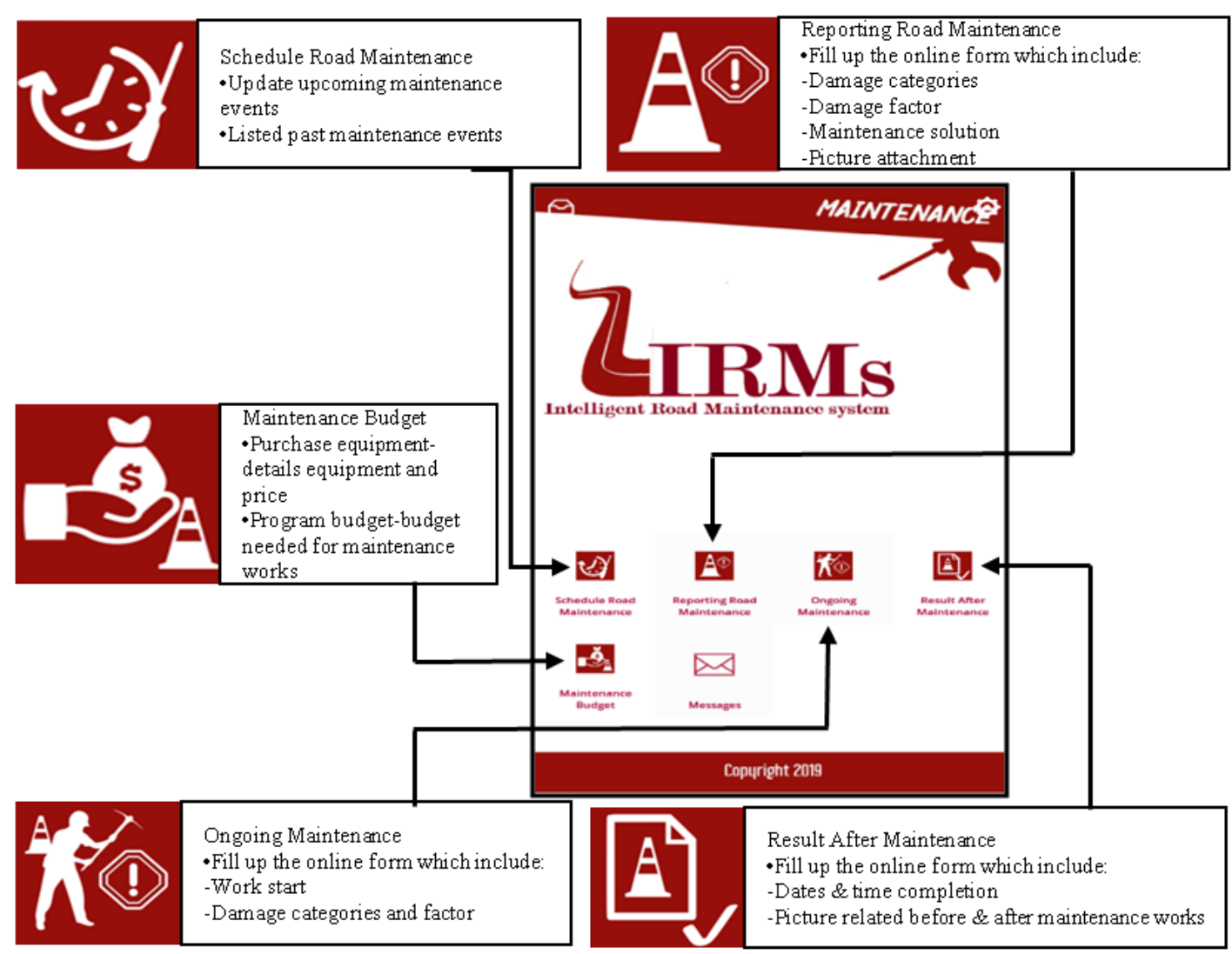

Figure 4. Intelligent road maintenance system (IRMs) mobile apps 
In schedule road maintenance it will update upcoming maintenance and listed past maintenance and it will help all the team know the info by using IRMs. For reporting road maintenance and ongoing maintenance, the road maintenance team need to fill up the online form mobile apps to make the detail easily keep for further action. All the data and detail road issues will send to email as summary report including picture attachment. After all the maintenance works have done, maintenance team will update the result through mobile apps which they need to fill up the online form that include date and time of completion work and the picture related before and after maintenance work.

\section{CONCLUSION}

Few highways around the world have successfully incorporated Mobile Devices in their highway management network, including Malaysian highways. The PLUS mobile app is the latest PLUS mobile application created by PLUS Malaysia Berhad and aims to provide Malaysian highway users with the most reliable traffic routing, road warnings and facilities available along PLUS highways. The intelligent road maintenance system (IRMs) which not yet introduce by PLUS mobile app shall be launched to public to notify the highway maintenance issues and can be more effective for road maintenance. IRMs mobile apps implementation to overcome the usual paper-based road survey reports which were manually entered into a system. Once this IRMs implemented, the maintenance personnel shall utilize their working hours to inspect road based on reports received from road user and road inspection. IRMs has attracted the concessionaires' attention to manage the highway traffic information. This app can be used to facilitate communication between the public and the PLUS highway concessionaire regards to condition of the transportation facilities, optimizing management workflow and improves the cost effectiveness of the management system.

\section{ACKNOWLEDGEMENTS}

The authors gratefully acknowledge the Universiti Tun Hussein Onn Malaysia especially to Department of Civil Engineering and Built Environment. This work was partially supported by the Artificial Intelligence Data Analytics Lab (AIDA), Prince Sultan University, Riyadh, Saudi Arabia.

\section{REFERENCES}

[1] A. I. Setianingsih, S. Sangaji, and A. Setyawan, "Road maintenance and rehabilitation program using functional and structural assessment," IOP Conference Series Material Science and Engineeering, vol. 176, no. 1, pp. 12030-1-6, 2017.

[2] W. F. Laurance and A. Balmford, "A global map for road building” Nature, vol. 495, no. 7441, pp. 308-309, 2013.

[3] W. F. Laurance, G. R. Clements, S. Sloan, C. S. O'connell, N. D. Mueller, M. Goosem, O. Venter, D. P. Edwards, B. Phalan, A. Balmford, and R. Van Der Ree, “A global strategy for road building,” Nature, vol. 513, no. 7517, pp. 229-232, 2014.

[4] A. Ghani, H. Lazim, H. Lamsali ans M. N. Salleh, "Highway maintenance management: A review of some practices in Malaysia," Journal of Technology and Operations Management, vol. 58, pp. 49-58, 2017.

[5] K. Levik, "How to sell the message "Road maintenance is necessary" to decision makers," First Road Transportation Technology Transfer Conference in Africa, 2001.

[6] H. Fares, K. Shahata, E. Elwakil, A. Eweda, T. Zayed, M. Abdelrahman, and I. Basha, "Modelling the performance of pavement marking in cold weather conditions," Struct. Infrastruct. Eng., vol. 8, no. 11, pp. 1067-1079, 2012.

[7] F. I. Zakaria, "Transport infrastructure is being improved from time to time to reduce accidents," In Malay, "Infrastruktur pengangkutan dibaiki dari semasa ke semasa kurangkan kemalangan," Utusan Malaysia, p. 6, March 2011.

[8] P. Kumar and A. Gupta, "Cases studies on failure of bituminous pavements," Proceedings of the 1st International Conference on Pavement Preservation, University of California, Berkeley Institute of Transportation Studies, Technology Transfer Program, vol. 7, pp. 505-518, 2010.

[9] H. H. Hizal and S. A. R. Sharifah Allyana, "The construction of road accident analysis and database system in Malaysia," in 4th IRTAD Conference, Seoul, pp. 235-241, 2009

[10] A. A. Abushnaf and A. Ismail, "The study of highway maintenance works in Selangor," Int. J. Innov. Res. Sci. Eng. Technol., vol. 4, no. 12, pp. 11712-11719, 2015.

[11] H. Sally and S. Natalya, "Why road maintenance is important and how to get it done," The World Bank, Washington D. Transport Note No. TRN-4, 2005.

[12] U. R. B. Emeasoba, "Sustainable socio-economic development in Nigeria: A case for road infrastructure maintenance," Journal of Environment and Earth Science, vol. 3, no. 5, pp. 129-137, 2013.

[13] A. Forster and C. A. Mensah, "enhancing urban roads maintenance in Ghana: Implications for sustainable urban development," Journal of Civil and Environmental Research, vol. 3, no. 12, pp. 63-76, 2013.

[14] A. H. Oluwasegun, "A GIS-based model for road maintenance in Nigeria: A case study of Ikeja road network, Lagos, Nigeria,” IOSR J. Humanit. Soc. Sci. Ver. IV, vol. 20, no. 5, pp. 16-26, 2015. 
[15] B. I. Chaney, J. Mcgowan-Martin, J. W. Perez, and T. J. Clark, "Intelligent transportation systems in New Mexico winter road maintenance," International Journal of Advanced Logistic, vol. 5, no. 1, pp. 19-29, 2016.

[16] I. M. Saleh, T. Toole, D. Bennett, and Z. Hasan, "Evaluation and monitoring of toll road pavements in Malaysia from an owner's perspective," 22nd ARRB Conference-Research and Practice, Canberra, pp. 1-17, 2006.

[17] I. Kamil, Julham, M. Lubis, and A. R. Lubis, "Management maintenance system for remote control based on microcontroller and virtual private serve," Indonesian Journal of Electrical Engineering and Computer Science, vol. 16, no. 3, pp. 1349-1355, 2019.

[18] T. Treeratanapon, "Design of the usability measurement framework for mobile applications," International Conference on Computer and Information Technology ICCIT', Bangkok, pp.71-75, 2012.

[19] J. Masino, J. Thumm, M. Frey, and F. Gauterin, "Learning from the crowd: Road infrastructure monitoring system," Journal of Traffic and Transportation Engineering (English Edition), vol. 4, no. 5, pp. 451-463, 2017.

[20] M. A. Osman, A. Z. Talib, Z. A. Sanusi, T. Shiang-Yen, and A. S. Alwi, "A study of the trend of smartphone and its usage behavior in Malaysia," Int. J. New Comput. Archit. Their Appl., vol. 2, no. 1, pp. 275-286, 2012.

[21] C. Sunitha, A. Jaya, and A. Ganesh, "Automatic summarization of Malayalam documents using clause identification method," International Journal of Electrical and Computer Engineering, vol. 9, no. 6, pp. 4929-4938, 2019.

[22] A. S. B. M. Noor, M. N. Y. Atoom, and R. Mamat, "A review of cloud oriented mobile learning platform and frameworks," International Journal of Electrical and Computer Engineering, vol. 9, no. 6, pp. 5529-5536, 2019.

[23] E. Babbie, "The practice of social research-9th ed.," Wadsworth Thomson, Belmont, 2001.

[24] J. F. Hair, B. Black, B. Babin, R. Anderson, and R. L. Tatham, "Multivariate data analysis-6th ed.," Englewood Cliffs, NJ: Prentice Hall, 2007.

[25] U. Sekaran and R. Bougie, "Research methods for business: A skill building approach-5th ed.," John Wiley \& Sons, 2011.

\section{BIOGRAPHIES OF AUTHORS}

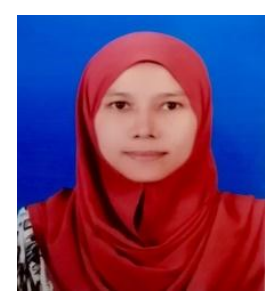

Nurul Husna Mohd Jamail pursuing PhD in Civil Engineering \& Built Environment, Universiti Tun Hussein Onn Malaysia (UTHM), Malaysia. Email: nurulhusnamj@yahoo.com

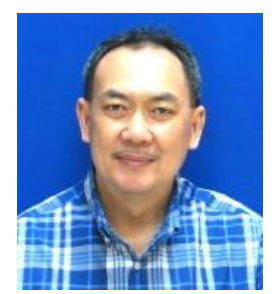

Abdul Halim A G, Prof Madya at department of Civil Engineering \& Built Environment, Universiti Tun Hussein Onn Malaysia (UTHM), Malaysia. Registered in Board of Engineers Malaysia (BEM). Email: abdulhalim@uthm.edu.my

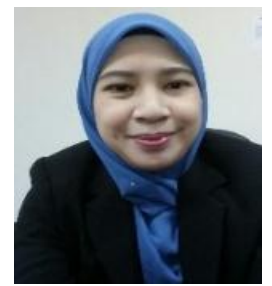

Dr. Nor Shahida Mohd Jamail is currently in Prince Sultan University, Riyadh, Saudi Arabia as an Assistant Professor. She obtained her PhD in Software Engineering from Universiti Putra Malaysia. Her specialized are purely in Software Engineering, Software Process Modelling, Software Testing and Cloud Computing Services. She had involved in Machine Learning Research Group in Prince Sultan University and also involved in research project which collaborated with National and International University. Email: njamail@psu.edu.sa 